\title{
Oxidation of benzoin catalyzed by oxovanadium (IV) schiff base complexes
}

Tahseen A Alsalim ${ }^{1}$, Jabbar S Hadi ${ }^{1}$, Omar N Ali ${ }^{1}$, Hanna S Abbo ${ }^{2}$ and Salam JJ Titinchi ${ }^{2 *}$

\begin{abstract}
Background: The oxidative transformation of benzoin to benzil has been accomplished by the use of a wide variety of reagents or catalysts and different reaction procedures. The conventional oxidizing agents yielded mainly benzaldehyde or/and benzoic acid and only a trace amount of benzil. The limits of practical utilization of these reagents involves the use of stoichiometric amounts of corrosive acids or toxic metallic reagents, which in turn produce undesirable waste materials and required high reaction temperatures.

In recent years, vanadium complexes have attracted much attention for their potential utility as catalysts for various types of reactions.
\end{abstract}

Results: Active and selective catalytic systems of new unsymmetrical oxovanadium(IV) Schiff base complexes for the oxidation of benzoin is reported. The Schiff base ligands are derived between 2-aminoethanol and 2-hydroxy-1naphthaldehyde $\left(\mathrm{H}_{2} \mathrm{~L}^{1}\right)$ or 3-ethoxy salicylaldehyde $\left(\mathrm{H}_{2} \mathrm{~L}^{3}\right)$; and 2-aminophenol and 3-ethoxysalicylaldehyde $\left(\mathrm{H}_{2} \mathrm{~L}^{2}\right)$ or 2-hydroxy-1-naphthaldehyde $\left(\mathrm{H}_{2} \mathrm{~L}^{4}\right)$. The unsymmetrical Schiff bases behave as tridentate dibasic ONO donor ligands. Reaction of these Schiff base ligands with oxovanadyl sulphate afforded the mononuclear oxovanadium(IV) complexes $\left(\mathrm{V}^{\mathrm{V}} \mathrm{OL}^{\mathrm{X}} \cdot \mathrm{H}_{2} \mathrm{O}\right)$, which are characterized by various physico-chemical techniques.

The catalytic oxidation activities of these complexes for benzoin were evaluated using $\mathrm{H}_{2} \mathrm{O}_{2}$ as an oxidant. The best reaction conditions are obtained by considering the effect of solvent, reaction time and temperature. Under the optimized reaction conditions, $\mathrm{VOL}^{4}$ catalyst showed high conversion (>99\%) with excellent selectivity to benzil $(\sim 100 \%)$ in a shorter reaction time compared to the other catalysts considered.

Conclusion: Four tridentate ONO type Schiff base ligands were synthesized. Complexation of these ligands with vanadyl(IV) sulphate leads to the formation of new oxovanadium(IV) complexes of type $\mathrm{V}^{\mathrm{IV}} \mathrm{OL} . \mathrm{H}_{2} \mathrm{O}$.

Elemental analyses and spectral data of the free ligands and their oxovanadium(IV) complexes were found to be in good agreement with their structures, indicating high purity of all the compounds.

Oxovanadium complexes were screened for the oxidation of benzoin to benzil using $\mathrm{H}_{2} \mathrm{O}_{2}$ as oxidant. The effect of time, solvent and temperature were optimized to obtain maximum yield. The catalytic activity results demonstrate that these catalytic systems are both highly active and selective for the oxidation of benzoin under mild reaction conditions.

Keywords: Tridentate ONO Schiff base ligands, Oxovanadium(IV) complexes, Benzoin oxidation, Benzil

\section{Background}

Liquid phase catalytic oxidation of alcohols is a fascinating reaction and is one of the most important synthetic reactions in organic chemistry. Oxidation of benzoin to benzil has been extensively studied for the production of fine chemicals [1-6]. In general $\alpha$-dicarbonyl compounds are

\footnotetext{
*Correspondence: stitinchi@uwc.ac.za

${ }^{2}$ Department of Chemistry, University of the Western Cape Bellville, Private Bag X17, Bellville, Cape Town 7535, South Africa

Full list of author information is available at the end of the article
}

important synthetic intermediates in the synthesis of many heterocyclic compounds. $\alpha$-Dicarbonyl compounds have diverse applications in organic and pharmaceutical industries such as photosensitive and synthetic reagents $[7,8]$ and photo initiators for radical polymerization [9]. Benzil, in particular, is a standard building block in organic synthesis and is utilized as an intermediate in the synthesis of chiral ligands and biologically active compounds.

The oxidative transformation of an $\alpha$-hydroxy ketone to the corresponding $\alpha$-diketone (benzoin to benzil) has

\section{() Chemistry Central}


been accomplished by the use of a wide variety of reagents or catalysts and different reaction procedures. Several reagents have been used for this transformation such as nitric acid, Th(III) and Y(III) nitrate [10] and bismuth(III) nitrate-copper(II) acetate [11]. The conventional oxidizing agents viz., permanganate, dichromate or chromic acid yielded chiefly benzaldehyde/benzoic acid and only a trace of benzil. The limits of practical utilization of these reagents involves the use of stoichiometric amounts of corrosive acids or toxic metallic reagents, which in turn produce undesirable waste materials and required high reaction temperatures.

In recent years, vanadium complexes have attracted much attention for their potential utility as catalysts for various types of reactions. Oxovanadium complexes catalyze various oxidation reactions viz., hydroxylation of phenols [12,13], oxidation of sulfides to sulfoxides $[14,15]$, oxidation of alcohols [15], epoxidation of olefins [15-19], hydroxylation of benzene to mono- and dihydroxybenzenes $[12,20,21]$ including reactions such as the coupling of 2-naphthols as well as Mannich-type reactions [22-25]. Most recently, the application of various oxovanadium complexes as catalysts in different oxidation reactions has been reviewed [26,27].

In this report we describe the synthesis of Schiff base ligands derived by reaction between 2-aminophenol or 2-aminoethanol and 2-hydroxy-1-naphthaldehyde or 3ethoxy salicylaldehyde to form tridentate dibasic ligands of the ONO type. Complexation of these ligands with vanadyl sulphate produced oxovanadium(IV) complexes. To the best of our knowledge, this is the first report describing the synthesis of these oxovanadium(IV) complexes.

As part of our continuing interest in oxidation reactions by vanadium complexes [13] and considering the demand of more efficient catalytic systems, we undertook an investigation of these oxovanadium(IV) complexes as catalysts for benzion oxidation for the first time.

\section{Results and discussion}

\section{Synthesis and characterization}

Facile condensation of 2-aminophenol or 2-aminoethanol and 2-hydroxy-1-naphthaldehyde or 3-ethoxy salicylaldehyde in 1:1 molar ratio afforded four Schiff base ligands viz. $\mathrm{H}_{2} \mathrm{~L}^{1}, \mathrm{H}_{2} \mathrm{~L}^{2}, \mathrm{H}_{2} \mathrm{~L}^{3}$ and $\mathrm{H}_{2} \mathrm{~L}^{4}$, respectively (Scheme 1 ). These tridentate ligands reacted readily with vanadyl sulfate in methanol to form the oxovanadium complexes with the same general structure (Scheme 2).

Spectral data and elemental analysis of all the synthesized ligands and their oxovanadium(IV) complexes were in good agreement with their structure, indicating the high purity of all the compounds.

The analytical data of the complexes indicates a 1:1 metal: ligand stoichiometry, and hence the Schiff bases act as tridentate dibasic ligands. These ligands can coordinate through the imino nitrogen and two oxygen atoms from the deprotonation of the phenolic groups as well as from the aliphatic hydroxyl group. The ligands react with $\mathrm{V}(\mathrm{IV})$ to fill three of the four equatorial coordination sites with a water molecule coordinating to the remaining site.

The IR spectra of the ligands and their complexes were compared to determine any changes during complexation and to confirm their structures (Additional file 1: Figure S1-S3). The IR spectra of the ligands showed a broad absorption band at $3230-3117 \mathrm{~cm}^{-1}$ attributed to the stretching vibration of intramolecular hydrogen bonded $\mathrm{OH}$ groups [28]. This band disappeared on complexation indicating the coordination of vanadium metal through $\mathrm{OH}$ groups after deprotonation. A new medium intensity band near $3400-3500 \mathrm{~cm}^{-1}$ is attributed to the $\mathrm{vOH}$ stretching vibration of the coordinated water molecule to the central metal ion [29]. A strong band at $1648-1629 \mathrm{~cm}^{-1}$ of the spectra of the ligand was assigned to the azomethine $(\mathrm{C}=\mathrm{N})$ stretching vibration. This band shifted to lower frequency (by $10-30 \mathrm{~cm}^{-1}$ ) in the complexes, indicating that the nitrogen atom of the azomethine group is coordinated to the metal centre $[30,31]$. The phenolic $v(\mathrm{C}-\mathrm{O})$ band at $1114-1116 \mathrm{~cm}^{-1}$ in the free ligand is shifted towards lower frequency by $10 \pm 15 \mathrm{~cm}^{-1}$ in the complexes, verifying coordination via the deprotonated phenolic oxygen. The complexes show a new strong band in the region between 975-987 $\mathrm{cm}^{-1}$ assigned to stretching vibration of $\mathrm{V}=\mathrm{O}[32,33]$ which indicates its monomeric nature [34]. The absence of significant bands in the frequency range below 900 $\mathrm{cm}^{-1}$ demonstrates no $\mathrm{V}=\mathrm{O} \cdots \mathrm{V}$ bridge vibration $[35,36]$. A similar monomeric nature of related complexes has also been well established crystallographically [37,38]. The appearance of two to three new moderately intense bands in the low-frequency region of $350-500 \mathrm{~cm}^{-1}$ in the complexes are assigned to stretching frequencies of $v(\mathrm{~V}-\mathrm{N})$ and $v(\mathrm{~V}-\mathrm{O})$ bonds i.e. coordination of azomethine nitrogen as well as phenolic oxygen to the vanadium metal after deprotonation. The $\mathrm{C}=\mathrm{C}$ stretching modes of the benzene ring of the ligand around 1600 $\mathrm{cm}^{-1}$ does not show any significant shift on complexation. Thus, the IR data indicates that the Schiff bases behave as dibasic tridentate ligands coordinating through phenolic and alcoholic oxygens and the azomethine nitrogen.

The ${ }^{1} \mathrm{H}$ NMR spectra of ligand $\mathrm{H}_{2} \mathrm{~L}^{1}$ and ligand $\mathrm{H}_{2} \mathrm{~L}^{3}$ displayed a broad signal corresponding to the $\mathrm{OH}$ proton of the ethanol amine moiety at 5.00 and $5.32 \mathrm{ppm}$, respectively. The phenolic $\mathrm{OH}$ protons appeared as broad signals at 13.88 and $13.70 \mathrm{ppm}$, respectively. The ${ }^{1} \mathrm{H}$ NMR spectra of ligands $\mathrm{H}_{2} \mathrm{~L}^{2}$ and $\mathrm{H}_{2} \mathrm{~L}^{4}$ displayed the $\mathrm{OH}$ phenolic groups as singlets at 9.77 and 14.2, and 
<smiles>OCC/N=C/c1c(O)ccc2ccccc12</smiles>

$L^{1}$

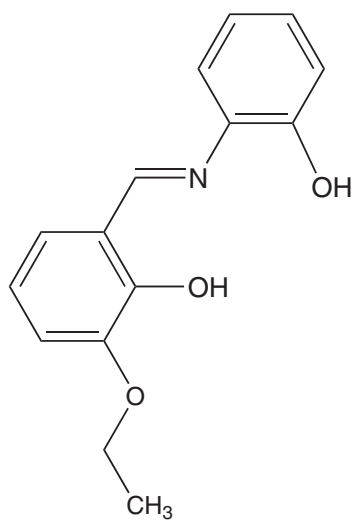

$L^{2}$

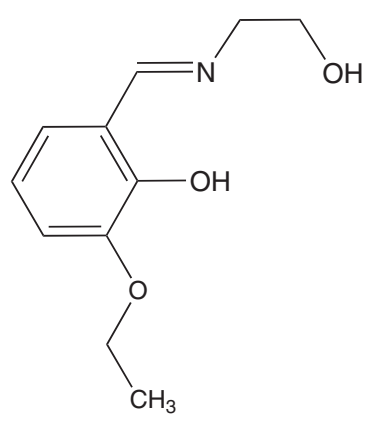<smiles>Oc1ccccc1/N=C/c1c(O)ccc2ccccc12</smiles>

$L^{3}$

Scheme 1 Structure of the ligands.

10.35 and $15.7 \mathrm{ppm}$, respectively [39]. In all the ligands the azomethine $\mathrm{HC}=\mathrm{N}$ proton appeared as a singlets at $8.35-9.43 \mathrm{ppm}$. All the other aromatic and aliphatic protons were observed in the expected regions (Additional file 1: Figure S4-S7).

The elemental analyses of the ligands and the complexes are in agreement with their formulation. The elemental analysis of the complexes confirms a 1:1 (metal: ligand) stiochiometry.

The result of mass spectra further indicates that the $\mathrm{V}$ (IV) complexes have a monomeric form of 1:1 stiochiometry, where the observed molecular ion peak $(\mathrm{m} / \mathrm{z})$ values are consistent with the calculated value in the proposed structure (Additional file 1: Figure S8-S11). The complexes were non-volatile and difficulties were experienced to record their mass spectra by E1 methods.

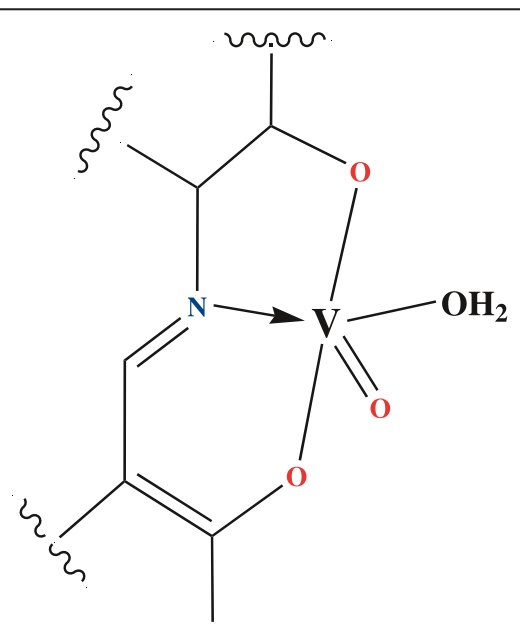

Scheme 2 General structure of oxovanadium(IV) complexes.

\section{Catalytic activity studies}

The catalytic activity of oxovanadium complexes for the oxidation of benzoin to benzil has been studied and the effect of time, solvent and temperature were optimized to produce maximum yield. Oxidation did not proceed when the reaction was carried out in the presence of either hydrogen peroxide or oxovanadium complexes only.

Progress of the reaction (as determined by the concentration of benzil) was monitored spectrophotometrically and identification of the product was confirmed by GCMS analyses which showed that benzil was the only product detectable. No oxidative cleavage products were observed.

The electronic spectrum of benzil is characterized by an absorption at $283 \mathrm{~nm}$, which is readily differentiated from the other absorption bands of benzil at $260 \mathrm{~nm}$ and benzoin $247 \mathrm{~nm}$ [40]. Accordingly, the band at $283 \mathrm{~nm}$ was used to determine the concentration of the produced benzil (Figure 1).

In order to screen the catalytic oxidative potential of the prepared complexes, they were tested for oxidation of benzoin using $\mathrm{H}_{2} \mathrm{O}_{2}$ as an oxidant under different reaction conditions viz., temperature, reaction time and type of solvent in order to optimise the conditions for the best performance of the catalyst.

Figure 2 shows that the absorbance at $283 \mathrm{~nm}$ increases with reaction time as an indication of the increasing concentration of benzil by using one of the catalysts, namely $\mathrm{VOL}^{1}$. The maximum benzil yield was found to depend upon the type of catalyst used (Figure 3). It is clear from Figure 3 that $\mathrm{VOL}^{4}$ and $\mathrm{VOL}^{1}$ give higher benzil yields compared to $\mathrm{VOL}^{3}$ and $\mathrm{VOL}^{2}$ with the same reaction time. $\mathrm{VOL}^{4}$ gave $100 \%$ yield after $2 \mathrm{~h}$, while $\mathrm{VOL}^{1}$ gave 


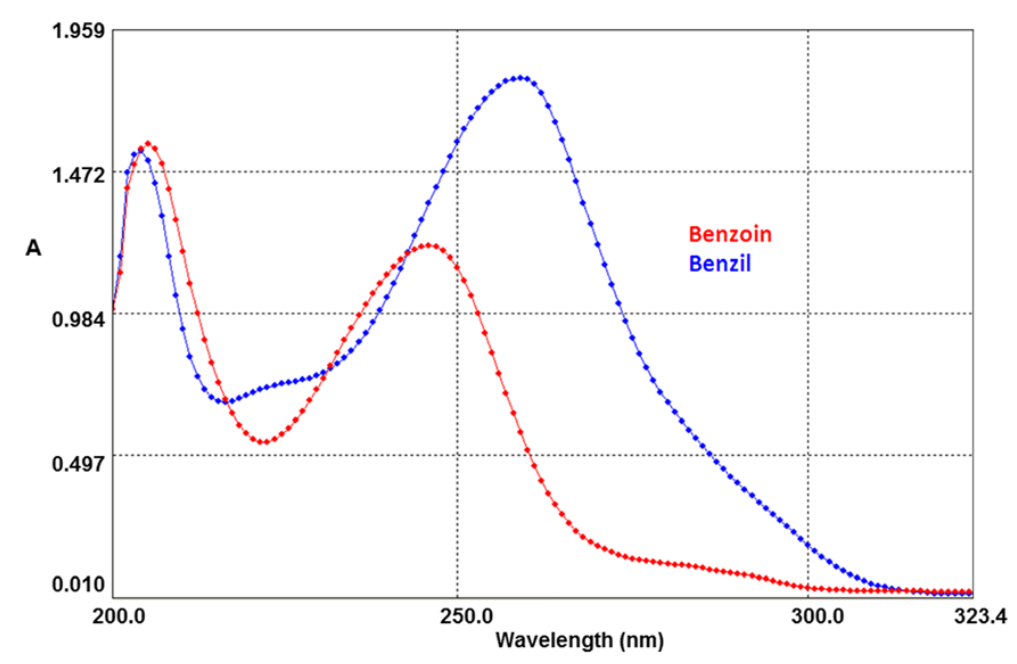

Figure 1 Absorption spectra of benzoin and benzil in acetonitrile.

98.9\% after a longer reaction time $(4 \mathrm{~h})$. The order of catalytic activity was found to be as follows: $\mathrm{VOL}^{4}>$ $\mathrm{VOL}^{1}>\mathrm{VOL}^{3}>\mathrm{VOL}^{2}$.

\section{Effect of solvent}

The influence of three different solvents viz. benzene, carbon tetrachloride and acetonitrile on the rate of benzoin oxidation was next studied.

Figures 4, 5, 6, 7 illustrate the effect of solvent upon the rate and yield of benzoin using catalysts $\left(\mathrm{VOL}^{1}-\mathrm{VOL}^{4}\right)$. It is clear from the figures that the solvent has no significant effect on the yield and selectivity. However, the reaction rate during the first four hours increases slightly as the polarity of the solvent decreases. Lower reaction rates were observed using the polar aprotic solvent, acetonitrile, compared to the other two solvents. On the other hand, the protic solvent, methanol, was not tried as it retards the oxidation of benzoin due to hydrogen bonding with the methanol [41].

In general, in these solvents, the order of the catalytic performance of these catalysts after $6 \mathrm{~h}$ reaction time as the following $\mathrm{VOL}^{1} \cong \mathrm{VOL}^{4}>\mathrm{VOL}^{3}>\mathrm{VOL}^{2}$.

\section{Effect of temperature}

The performance of the catalysts was investigated at two different temperatures viz. $30^{\circ} \mathrm{C}$ and $50^{\circ} \mathrm{C}$ in benzene after $5 \mathrm{~h}$ reaction time (Figure 8).

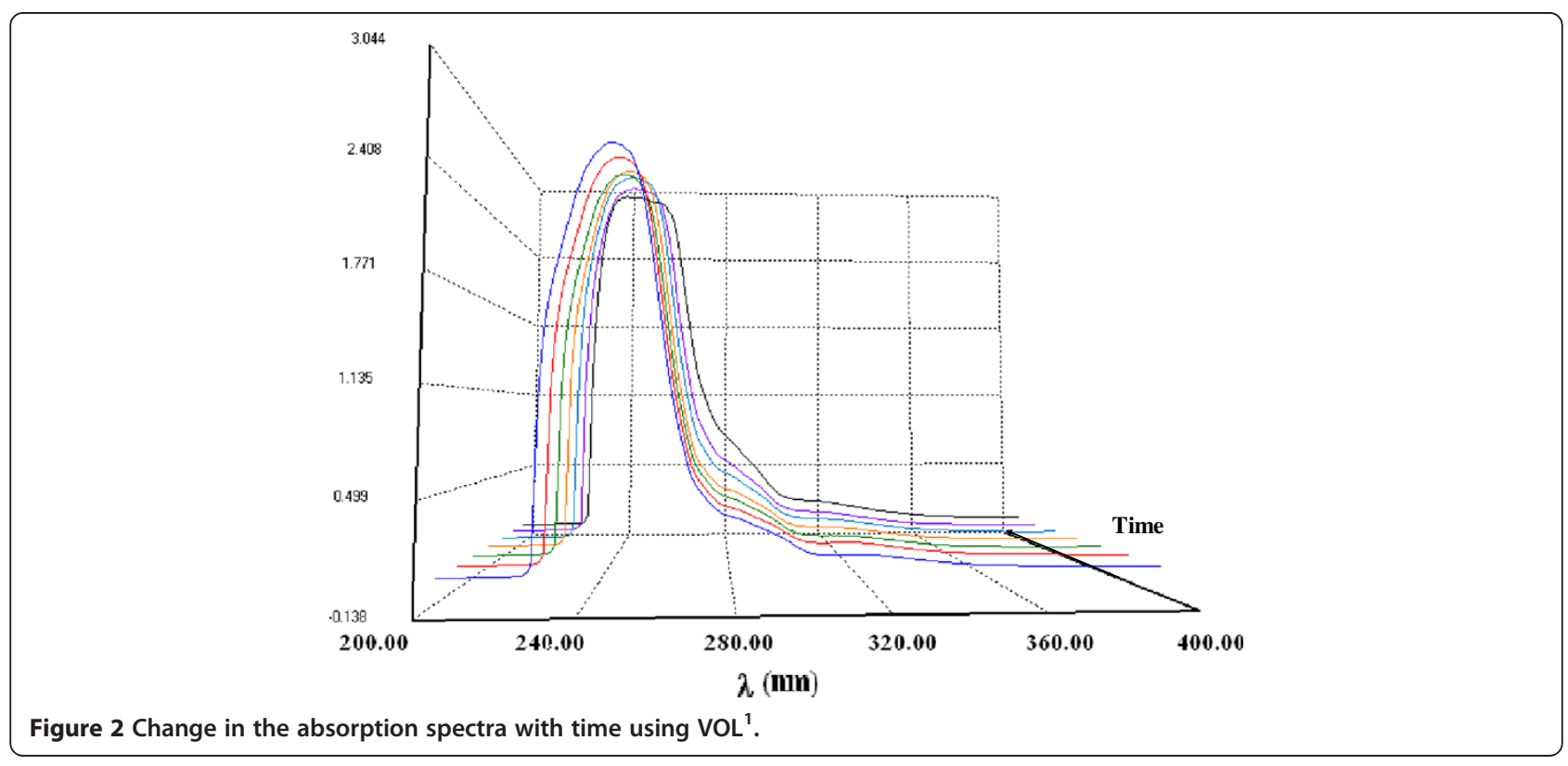




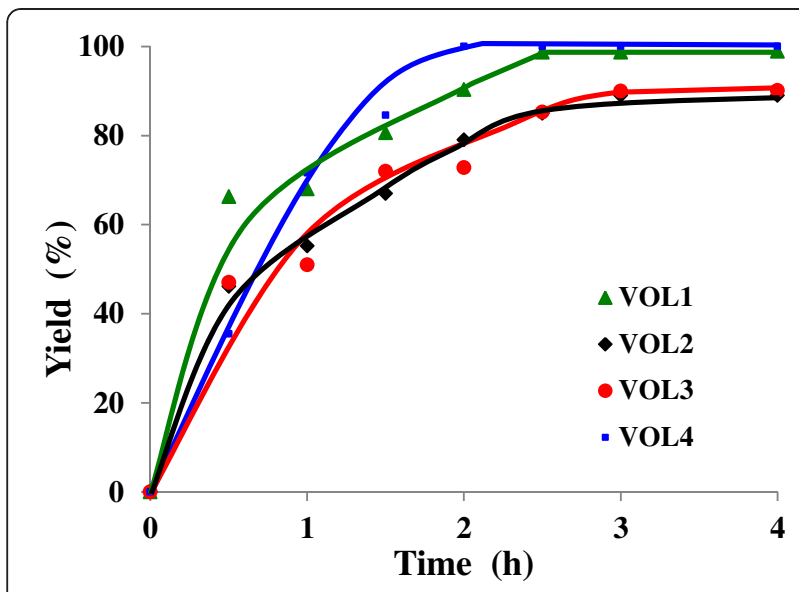

Figure 3 Catalytic performance of the different catalysts with time for the formation of benzil in benzene at $50^{\circ} \mathrm{C}$.

In general, the catalytic activity of the four catalysts increased with increasing temperature. Figure 8 shows that there was a significant increase in benzil yield using $\mathrm{VOL}^{1}, \mathrm{VOL}^{2}$ and $\mathrm{VOL}^{3}$ when the reaction temperature was increased from $30^{\circ} \mathrm{C}$ to $50^{\circ} \mathrm{C}$; while $\mathrm{VOL}^{4}$ gave a high benzil yield (97\%) even at the lower temperature i.e. $30^{\circ} \mathrm{C}$ and a minor increase at $50^{\circ} \mathrm{C}$. At $30^{\circ} \mathrm{C}$, moderate yields of benzil were observed in all three solvents. However, the increase in reaction temperature to $50^{\circ} \mathrm{C}$ led to almost complete conversion of benzoin to benzil. Excellent selectivity was observed with all the catalysts. Thus from the results above it is clear that $50^{\circ} \mathrm{C}$ is the optimum temperature for this oxidation. All the catalysts possess excellent selectivity towards benzil formation.

\section{Effect of time}

The catalytic oxidation of benzoin using $\mathrm{H}_{2} \mathrm{O}_{2}$ as oxidant in the presence of the four catalysts was followed

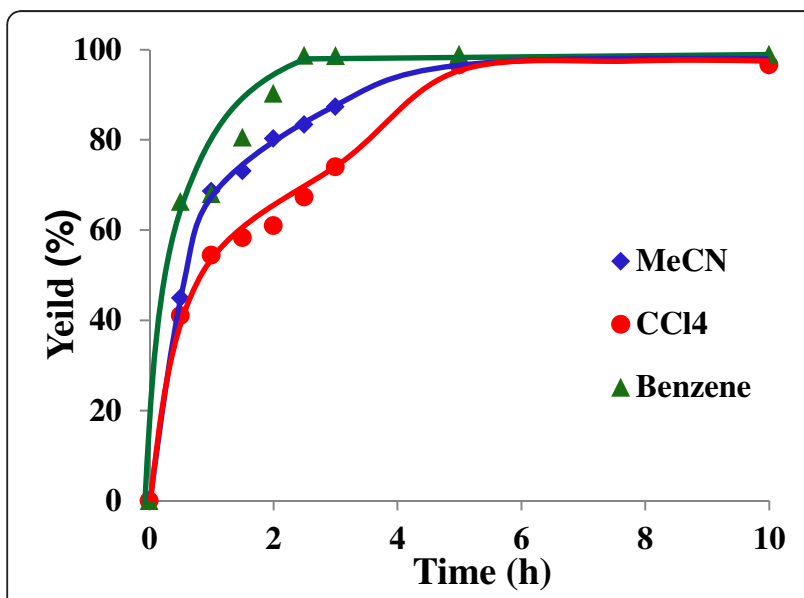

Figure 4 Effect of solvent on \% yield of benzil using $\mathrm{VOL}^{1}$ at $50^{\circ} \mathrm{C}$.

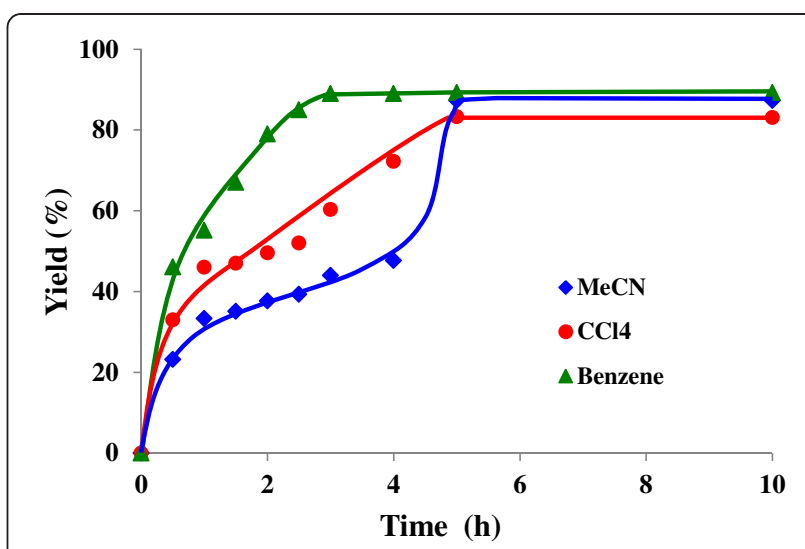

Figure 5 Effect of solvent on \% yield of benzil using $\mathrm{VOL}^{2}$ at $50^{\circ} \mathrm{C}$.

as a function of time in benzene at $50^{\circ} \mathrm{C}$. The reaction profiles (Figure 3) showed that the yield of benzil increased with increasing reaction time until a steady state was reached after 2-4 h. However, maximum yield of benzil (>99.9\%) was obtained using $\mathrm{VOL}^{1}$ and $\mathrm{VOL}^{4}$, and ca. 90\% using $\mathrm{VOL}^{2}$ and $\mathrm{VOL}^{3}$. $\mathrm{VOL}^{4}$ achieved the maximum conversion within a shorter reaction time than the other catalysts. The selectivity of all the catalysts was found to be unaffected with increasing reaction time i.e. $>99.9 \%$ benzil.

\section{Experimental section}

\section{Materials}

Oxavanadium sulfate trihydrate, 2-aminophenol and 2hydroxy-1-naphthaldehyde were obtained from Fluka, 2aminoethanol, 3-ethoxysalicylaldehyde and benzoin were obtained from Merck $30 \% \mathrm{H}_{2} \mathrm{O}_{2}$. All other chemical reagents were used as such. Solvents were used after being purified according to the standard methods.

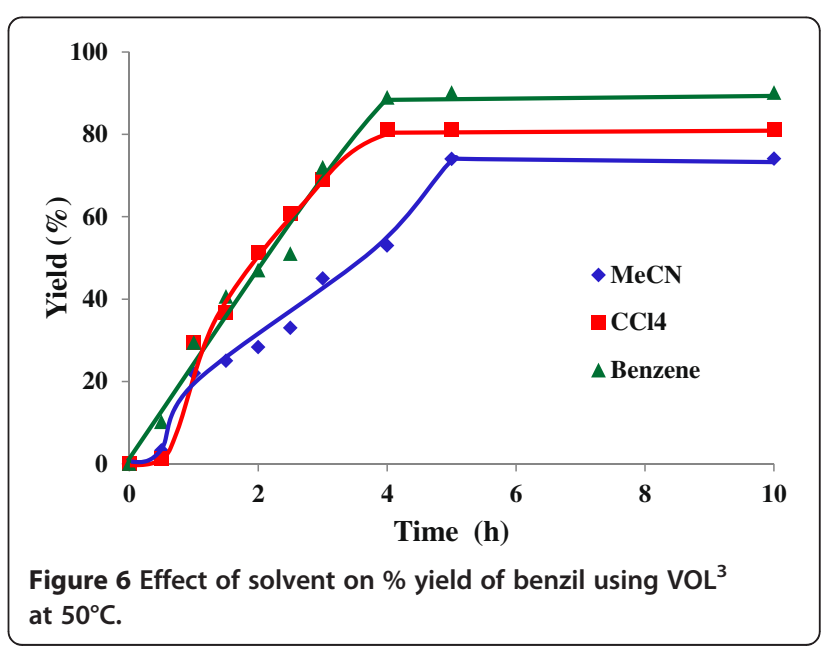




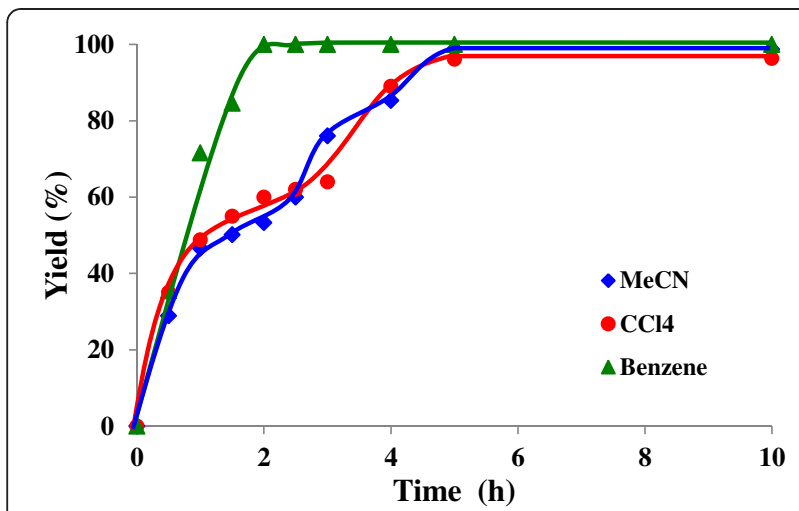

Figure 7 Effect of solvent on \% yield of benzil using $\mathrm{VOL}^{4}$ at $50^{\circ} \mathrm{C}$.

\section{Physical methods and analysis}

Infrared spectra were recorded as $\mathrm{KBr}$ pellets on a BUCK500 FT-IR spectrometer. ${ }^{1} \mathrm{H}$ NMR spectra were recorded on a Bruker $500(500 \mathrm{MHz})$ spectrometer using DMSO- $\mathrm{d}_{6}$ as a solvent and TMS as internal standard. GC-MS were recorded on a Hewlett Packard E1 mass spectrometer at $70 \mathrm{eV}$. Elemental analysis was performed on Euro Vectro EA 3000A analyzer. All catalyzed reaction products were analyzed using UV-vis PG Instrument T- $80^{+}$.

\section{Preparation methods}

\section{General method for preparation of Schiff base ligands}

Methanolic solutions of the aldehyde and amine were mixed at room temperature in a 1: 1 molar ratio using glacial acetic acid as a catalytic agent. The resulting mixture was refluxed for $2 \mathrm{~h}$. The crystalline product was obtained from the deep-yellow coloured solution after standing for a few hours at $25^{\circ} \mathrm{C}$. The precipitate was filtered off and washed with ice-cold methanol. The pure compound was obtained by recrystallization from a suitable solvent.

$\mathrm{H}_{2} \mathrm{~L}^{1}$ 1-\{[(2-hydroxyethyl)imino]methyl $\}$-2-naphthol

2-Hydroxy-1-naphthaldehyde (1.72 g), 2-aminoethanol (0.61 g), (69\% yield) as orange needles (from ethanol);

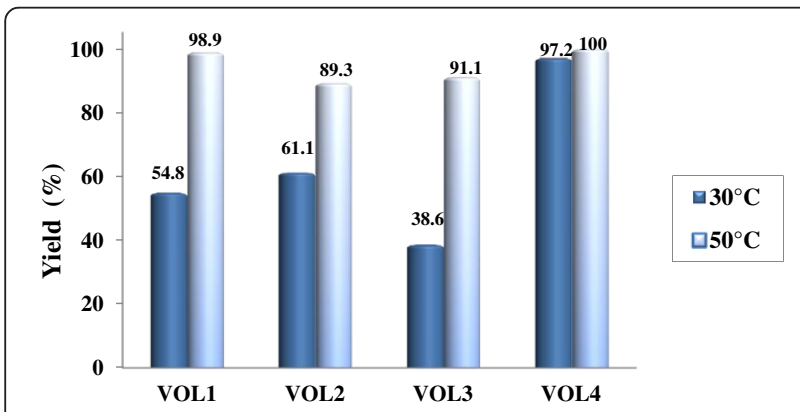

Figure 8 Catalytic performance of the catalysts for the oxidation of benzoin at two reaction temperatures in benzene after $5 \mathrm{~h}$ reaction time. mp $148-150^{\circ} \mathrm{C}$. Anal. Found: C, 71.69; H, 5.73; N, 6.09. $\mathrm{C}_{13} \mathrm{H}_{13} \mathrm{NO}_{2}$ requires $\mathrm{C}, 72.54 ; \mathrm{H}, 6.09 ; \mathrm{N}, 6.51 \%$. IR $\left(\mathrm{KBr}, \mathrm{cm}^{-1}\right), 3167 \mathrm{br}(\mathrm{vOH}), 3056$ (vC-H Ar), 2917 (vC-H aliph.), $1641(\mathrm{vC}=\mathrm{N}) ;{ }^{1} \mathrm{H}$ NMR (DMSO-d $\left.\mathrm{d}_{6}, \delta / \mathrm{ppm}\right): 3.65$ $\left(\mathrm{m}, 4 \mathrm{H}, 2 \mathrm{CH}_{2}\right), 5.00(\mathrm{br}, 1 \mathrm{H}, \mathrm{OH}), 6.64-8.00(\mathrm{~m}, 6 \mathrm{H}$, $\mathrm{Ar}-\mathrm{H})$, 9.02(s, $1 \mathrm{H}, \mathrm{HC}=\mathrm{N}), 13.88(\mathrm{br}, 1 \mathrm{H}$, phenolic $\mathrm{OH})$; $\mathrm{m} / \mathrm{z} \mathrm{M}^{++}=215$ (85\%), 214 (66\%), 184 (base peak), 170 (42\%). Found 215.00, $\mathrm{C}_{13} \mathrm{H}_{13} \mathrm{NO}_{2}$ requires 215.25.

$\mathrm{H}_{2} \mathrm{~L}^{2}$ 2-ethoxy-6-\{[(2-hydroxyphenyl)imino]methyl $\}$ phenol

3-Ethoxysalicylaldehyde (1.66 g), 2-aminophenol (1.09 g), (87\% yield) as reddish orange needles (from ethanol); $\mathrm{mp}$ 172-174 ${ }^{\circ}$ C. Anal. Found: C, 69.17; H, 5.41; N, 5.13. $\mathrm{C}_{15} \mathrm{H}_{15} \mathrm{NO}_{3}$ requires $\mathrm{C}, 70.02 ; \mathrm{H}, 5.88 ; \mathrm{N}, 5.44 \%$. IR (KBr, $\mathrm{cm}^{-1}$ ), 32100 ( $(\mathrm{OH}), 3060$ (vC-H Ar), 2986 (vC-H aliph.), $1629 \mathrm{~s}(\mathrm{vC}=\mathrm{N}) .{ }^{1} \mathrm{H}$ NMR (DMSO-d $\left.{ }_{6}, \delta / \mathrm{ppm}\right): 1.3(\mathrm{t}, 3 \mathrm{H}$, $\mathrm{CH}_{3}$ ), 4.06 (q, 2H, 2CH $\mathrm{CH}_{2}$ ), 6.78-7.38 (m, 7H, Ar-H), 8.94 (s, $1 \mathrm{H}, \mathrm{HC}=\mathrm{N}$ ), 9.77 (s, $1 \mathrm{H}, \mathrm{OH}$; amino phenol moiety), 14.20 (s, $1 \mathrm{H}, \mathrm{OH}$; 3-ethoxysalicylaldehyde moiety). $\mathrm{m} / \mathrm{z} \mathrm{M}^{+}=$ 257 (86\%), 242 (41\%) $\quad\left[\mathrm{M}-\mathrm{CH}_{3}\right]^{+}, 212$ (24\%) [M$\left.\mathrm{OCH}_{2} \mathrm{CH}_{3}\right]^{++}, 120$ (55\%), 69 (base peak). Found 257.00, $\mathrm{C}_{15} \mathrm{H}_{15} \mathrm{NO}_{3}$ requires 257.29.

$\mathrm{H}_{2} \mathrm{~L}^{3}$ 2-ethoxy-6- $\{[(2$-hydroxyethyl)imino $]$ methyl $\}$ phenol

3-Ethoxysalicylaldehyde (1.66 g), 2-aminoethanol (0.61 g), (81\% yield) as yellow crystals (from ethanol); mp 88-90 ${ }^{\circ}$. Anal. Found: C, 62.25; H, 6.91; N, 6.41. $\mathrm{C}_{11} \mathrm{H}_{15} \mathrm{NO}_{3}$ requires $\mathrm{C}, 63.14 ; \mathrm{H}, 7.23 ; \mathrm{N}, 6.69 \%$. IR $\left(\mathrm{KBr}, \mathrm{cm}^{-1}\right), 3230(\mathrm{vOH}), 3050$ (vC-H Ar), 2953-2866 (vC-H aliph.), $1652(\mathrm{vC}=\mathrm{N}) .{ }^{1} \mathrm{H}$ NMR (DMSO-d $6, \delta /$ ppm): $1.6\left(\mathrm{t}, 3 \mathrm{H}, \mathrm{CH}_{3}\right), 3.70\left(\mathrm{t}, 2 \mathrm{H}, \mathrm{CH}_{2}\right.$ of $\left.\mathrm{CH}_{2} \mathrm{~N}=\mathrm{CH}\right)$, $3.90\left(\mathrm{t}, 2 \mathrm{H}, \mathrm{CH}_{2}\right.$ of $\left.\mathrm{CH}_{2} \mathrm{OH}\right), 5.32(\mathrm{~s}, 1 \mathrm{H}, \mathrm{OH}), 6.70-7.91$ $(\mathrm{m}, 3 \mathrm{H}, \mathrm{Ar}-\mathrm{H}), 8.35(\mathrm{~s}, 1 \mathrm{H}, \mathrm{HC}=\mathrm{N}), 13.70(\mathrm{br}, 1 \mathrm{H}, \mathrm{OH}$ phenolic $\mathrm{OH}) ; \mathrm{m} / \mathrm{z} \mathrm{M} \mathrm{M}^{+}=209(13 \%) \mathrm{C}_{11} \mathrm{H}_{15} \mathrm{NO}_{3}, 194$ (20\%) $\left[\mathrm{M}-\mathrm{CH}_{3}\right]^{++}, 164$ (25\%) $\left[\mathrm{M}-\mathrm{OCH}_{2} \mathrm{CH}_{3}\right]^{++}, 69$ (base peak) $\left(\mathrm{C}_{2} \mathrm{H}_{5} \mathrm{NO}^{+}\right)$. Found 209.00, $\mathrm{C}_{11} \mathrm{H}_{15} \mathrm{NO}_{3}$ requires 209.23.

$\mathrm{H}_{2} \mathrm{~L}^{4} 1$ - $\{[(2$-hydroxyphenyl)imino $]$ methyl $\}$-2-naphthol

2-Hydroxy-1-naphthaldehyde (1.72 g), 2-aminophenol (1.09 g), (63\% yield) as orange needles (from ethanol); mp 247-249 ${ }^{\circ}$ C. Anal. Found: C, 76.64; H, 4.34; N, 4.96. $\mathrm{C}_{17} \mathrm{H}_{13} \mathrm{NO}_{2}$ requires $\mathrm{C}, 77.55 ; \mathrm{H}, 4.98 ; \mathrm{N}, 5.32 \%$. IR $\left(\mathrm{KBr}, \mathrm{cm}^{-1}\right), 3117(\mathrm{vOH}), 3053$ (vC-H Ar), 2960 ( $v \mathrm{C}-\mathrm{H}$ aliph.), $1622(v \mathrm{C}=\mathrm{N}) .{ }^{1} \mathrm{H}$ NMR (DMSO-d $\left.{ }_{6}, \delta / \mathrm{ppm}\right)$ : 6.74-8.35 (m, 10H, Ar-H), $9.43(\mathrm{~s}, 1 \mathrm{H}, \mathrm{HC}=\mathrm{N}), 10.35$ (s, 1H, OH phenolic), 15.70 (s, $1 \mathrm{H}, \mathrm{OH}$ naphthoyl); m/z $\mathrm{M}^{+}=263(75 \%), 262$ (base peak) $[\mathrm{M}-\mathrm{H}]^{+}$. Found 263.00. $\mathrm{C}_{17} \mathrm{H}_{13} \mathrm{NO}_{2}$ requires 263.30.

\section{Preparation of the oxavanadium (IV) complexes}

All complexes were prepared according to the following procedure: a hot methanolic solution of $\mathrm{VOSO}_{4} \cdot 3 \mathrm{H}_{2} \mathrm{O}$ $(0.217 \mathrm{~g}, 1 \mathrm{mmol})$, was added drop wise to a hot methanolic solution of the ligand $(1.5 \mathrm{mmol})$. The resulting mixture was stirred for $3 \mathrm{~h}$ and the products obtained 
were filtered, washed with hot water then methanol and dried in air at $90^{\circ} \mathrm{C}$.

$\mathrm{VOL}^{1}$ Dark green ppt., $\mathrm{mp}>300^{\circ} \mathrm{C}$, IR $\left(\mathrm{KBr}, \mathrm{cm}^{-1}\right)$; 3050 (vC-H arom.), 2936 ( $v \mathrm{C}-\mathrm{H}$ aliph.) 1614 $(v \mathrm{C}=\mathrm{N})$, $1512(v \mathrm{C}=\mathrm{C}), 1322(v \mathrm{C}-\mathrm{N}), 1198(v-\mathrm{O}), 975(v \mathrm{~V}=\mathrm{O})$. Anal. Calcd. for $\mathrm{C}_{13} \mathrm{H}_{13} \mathrm{NO}_{4} \mathrm{~V}$ : C, 52.35; H, 4.36; N, 4.69. Found: C, 52.51; H, 4.23; N, 4.51. $\mathrm{m} / \mathrm{z} \mathrm{M}^{++}=298$.

$\mathrm{VOL}^{2}$ Brown ppt., $\mathrm{mp}>300^{\circ} \mathrm{C}$, IR $\left(\mathrm{KBr}, \mathrm{cm}^{-1}\right) ; 3053$ (vC-H arom.), 2969-2890 (vC-H aliph.), $1601(v C=\mathrm{N})$, $1582(v \mathrm{C}=\mathrm{C}), 1294(v \mathrm{C}-\mathrm{N}), 1248(v \mathrm{C}-\mathrm{O}), 987(v \mathrm{~V}=\mathrm{O})$. Anal. calcd. for $\mathrm{C}_{15} \mathrm{H}_{15} \mathrm{NO}_{5} \mathrm{~V}$ : C, 52.95; H, 4.41; N, 4.11.

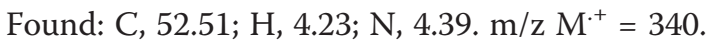

$\mathrm{VOL}^{3}$ Green ppt., $\mathrm{mp}>300^{\circ} \mathrm{C}$, IR $\left(\mathrm{KBr}, \mathrm{cm}^{-1}\right) ; 3080(\mathrm{vC}-$ $\mathrm{H}$ arom.), 2951 (vC-H aliph.), $1608(\mathrm{vC}=\mathrm{N}), 1505$ $(v \mathrm{C}=\mathrm{C}), 1334(v \mathrm{C}-\mathrm{N}), 1212(v \mathrm{C}-\mathrm{O}), 981(v \mathrm{~V}=\mathrm{O})$. Anal. calcd. for $\mathrm{C}_{11} \mathrm{H}_{15} \mathrm{NO}_{5} \mathrm{~V}: \mathrm{C}, 45.21 ; \mathrm{H}, 5.31 ; \mathrm{N}, 4.79$. Found: C, 45.54; H, 5.23; N, 4.57. $\mathrm{m} / \mathrm{z} \mathrm{M}^{+}=292$.

$\mathrm{VOL}^{4}$ Dark green ppt., $\mathrm{mp}>300^{\circ} \mathrm{C}$, IR $\left(\mathrm{KBr}, \mathrm{cm}^{-1}\right) ; 3067$ (vC-H arom.), 2961 (vC-H aliph.), $1592(v \mathrm{C}=\mathrm{N}), 1575$ $(v \mathrm{C}=\mathrm{C}), 1338(v \mathrm{C}-\mathrm{N}), 1177(v \mathrm{C}-\mathrm{O}), 978(v \mathrm{~V}=\mathrm{O})$. Anal. calcd . for $\mathrm{C}_{17} \mathrm{H}_{13} \mathrm{NO}_{4} \mathrm{~V}$ : C, 58.96; $\mathrm{H}, 3.75 ; \mathrm{N}, 4.04$.

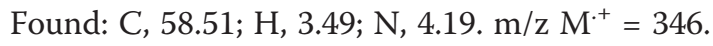

\section{Catalytic activity study}

The catalytic oxidation of benzoin to benzil was carried out in a $25 \mathrm{ml}$ flask. In a typical reaction, an aqueous solution of $30 \% \mathrm{H}_{2} \mathrm{O}_{2}(0.015 \mathrm{mmol})\left(0.5 \mathrm{~mL}\right.$ of $\mathrm{H}_{2} \mathrm{O}_{2}$ stock solution; $0.017 \mathrm{~g}$ in $\left.5 \mathrm{~mL} \mathrm{CH} \mathrm{CH}_{3} \mathrm{CN}\right)$ and benzoin $(0.01 \mathrm{~g}$, $0.047 \mathrm{mmol}$ ) were mixed in $3 \mathrm{~mL}$ of the solvent used and the reaction mixture was magnetically stirred and heated at $30^{\circ} \mathrm{C}$ or $50^{\circ} \mathrm{C}$ in an oil bath. An appropriate amount of catalyst $(0.003 \mathrm{~g})$ was added to the reaction mixture and with this, the reaction was considered to begin. Each run was repeated twice. During the reaction, the products were analysed after specific time intervals using UV-vis spectroscopy and later confirmed by GC after considering the response factors of the authentic samples. Samples of the reaction mixture $(0.1 \mathrm{ml})$ were diluted with $10 \mathrm{ml}$ mixture of $\mathrm{H}_{2} \mathrm{O}: \mathrm{CH}_{3} \mathrm{CN}(1: 1)$ and the absorbance of the solution was measured spectrophotometrically The effects of various parameters, such as time of reaction and type of solvent as well as the temperature of the reaction were studied in order to examine their effect on the reaction product pattern.

\section{Conclusion}

Four tridentate ONO type Schiff base ligands were synthesized by condensation of 2-aminophenol or 2-aminoethanol with 3-ethoxy salicylaldehyde and 2-hydroxy-1-naphthaldehyde. Complexation of these ligands with vanadyl(IV) sulphate leads to the formation of new oxovanadium(IV) complexes of type $\mathrm{V}^{\mathrm{IV}} \mathrm{OL} \cdot \mathrm{H}_{2} \mathrm{O}$.

Elemental analyses and spectral data of the free ligands and their oxovanadium(IV) complexes were found to be in good agreement with their structures, indicating high purity of all the compounds.

Oxovanadium complexes were screened for the oxidation of benzoin to benzil using $\mathrm{H}_{2} \mathrm{O}_{2}$ as oxidant. The effect of time, solvent and temperature were optimized to obtain maximum yield. The catalytic activity results demonstrate that these catalytic systems are both highly active and selective for the oxidation of benzoin under mild reaction conditions.

\section{Additional file}

Additional file 1: Figure S1. Ft-IR spectrum of $\mathrm{H}_{2} \mathrm{~L}^{1}$. Figure S2: FT-IR spectrum $\mathrm{H}_{2} \mathrm{~L}^{2}$.Figure S3: FT-IR spectrum VOL ${ }^{2}$. Figure S4: $\mathrm{H}-\mathrm{NMR}$ spectrum $\mathrm{H}_{2} \mathrm{~L}^{1}$. Figure S5: $\mathrm{H}-\mathrm{NMR}$ spectrum $\mathrm{H}_{2} \mathrm{~L}^{2}$. Figure S6: $\mathrm{H}-\mathrm{NMR}$ spectrum $\mathrm{H}_{2} \mathrm{~L}^{3}$. Figure S7: $\mathrm{H}-\mathrm{NMR}$ spectrum $\mathrm{H}_{2} \mathrm{~L}^{4}$. Figure S8: Mass spectra $\mathrm{H}_{2} \mathrm{~L}^{1}$. Figure S9: Mass spectra $\mathrm{H}_{2} \mathrm{~L}^{2}$. Figure S10: Mass spectra $\mathrm{H}_{2} \mathrm{~L}^{3}$. Figure S11: Mass spectra $\mathrm{H}_{2} \mathrm{~L}^{4}$.

\section{Competing interests}

The authors declare that they have no competing interests.

\section{Authors' contributions}

OA carried out the experimental work. TA helped in experimental and discussion part. JH helped in experimental and discussion part. HA helped in the discussion, characterization and draft the manuscript. ST helped in the discussion, characterization and draft the manuscript. All authors read and approved the final manuscript.

\section{Author details}

${ }^{1}$ Department chemistry, College of Education, University of Basrah, Basrah, Iraq. ${ }^{2}$ Department of Chemistry, University of the Western Cape Bellville, Private Bag X17, Bellville, Cape Town 7535, South Africa.

Received: 13 November 2012 Accepted: 2 January 2013

Published: 7 January 2013

\section{References}

1. Mallat T, Biker A: Oxidation of alcohols with molecular oxygen on solid catalysts. Chem Rev 2004, 104:3037-3058.

2. Ebitani K, Ji H-B, Mizugaki T, Kaneda K: Highly active trimetallic Ru/CeO2/ $\mathrm{CoO}(\mathrm{OH})$ catalyst for oxidation of alcohols in the presence of molecular oxygen. J Mol Catal A: Chem 2004, 212:161-170.

3. Makwana VD, Son Y-C, Howell AR, Suib SL: The role of lattice oxygen in selective benzyl alcohol oxidation using OMS-2 catalyst: A kinetic and isotope-labeling study. J Catal 2002, 210:46-52.

4. Kobayashi S, Miyamura H, Akiyama R, Ishid T: Highly active, immobilized ruthenium catalysts for oxidation of alcohols to aldehydes and ketones. Preparation and use in both batch and flow systems. J Am Chem Soc 2005, 127:9251-9254.

5. Ferri D, Mondelli C, Krumeich F, Baiker A: Discrimination of active palladium sites in catalytic liquid-phase oxidation of benzyl alcohol. $J$ Phys Chem B 2006, 110:22982-22986.

6. Jensen DR, Sigman MS: Palladium catalysts for aerobic oxidative kinetic resolution of secondary alcohols based on mechanistic insight. Org Lett 2003, 5:63-65.

7. Vollhardt KPC, Schore NE: Organic Chemistry. New York: 2nd ed, Freeman; 1994:924-929.

8. Kirihara M, Ochiai Y, Takizawa S, Takahata H, Nemoto H: Aerobic oxidation of a-hydroxycarbonyls catalysed by trichlorooxyvanadium: Efficient synthesis of a-dicarbonyl compounds. Chem Commun 1999, :1387-1388.

9. Siegel H, Eggersdorfer M: Ketones in Ullmann's Encyclopaedia of Industrial Chemistry. Wienheim: Wiley-VCH; 2002.

10. McKillop A, Swann B, Ford ME, Taylor EC: Thallium in organic synthesis. XXXVIII. Oxidation of chalcones, deoxybenzoins, and benzoins with thallium(III) nitrate (TTN). J Am Chem Soc 1973, 95:3641-3645. 
11. Tymonko SA, Nattier BA, Mohan RS: Oxidation of benzoins to benzils using bismuth(III) nitrate-copper(II) acetate.). Tetrahedron Lett 1999, 40:7657-7659.

12. Maurya MR, Kumar M, Titinchi SJJ, Abbo HS, Chand S: Oxovanadium(IV) Schiff base complexes encapsulated in zeolite-Y as catalysts for the liquid-phase hydroxylation of phenol. Catal Lett 2003, 86:97-105.

13. Alsalim TA, Hadi JS, Al-Nasir EA, Abbo HS, Titinchi SJJ: Hydroxylation of phenol catalyzed by oxovanadium(IV) of salen-type schiff base complexes with hydrogen peroxide.). Catal Lett 2010, 136:228-233.

14. de Azevedo Marques AP, Dockal ER, Skrobot FC, Viana Rosa IL: Synthesis, characterization and catalytic study of [N, N/-bis(3-ethoxysalicylidene)-mxylylenediamine]oxovanadium(IV) complex. Inorg Chem Commun 2007, 10:255-261.

15. Bunce $S$, Cross RJ, Farrugia L, Kunchandy S, Meason LL, Muir KW, O'Donnell M, Peacock RD, Stirling D, Teat SJ: Chiral Schiff base complexes of copper (II), vanadium (IV) and nickel (II) as oxidation catalysts. X-ray crystal structures of [cu (R-salpn) (OH 2)] and [cu ( \pm -busalcx)]. Polyhedron 1998, 17:4179-4187.

16. Maurya MR, Bisht M, Avecilla F: Synthesis, characterization and catalytic activities of vanadium complexes containing ONN donor ligand derived from 2-aminoethylpyridine. J Mol Catal A: Chem 2011, 344:18-27.

17. Walmsley RS, Tshentu ZR: Imidazole-based vanadium complexes as haloperoxidase models for oxidation reactions. S Afr J Chem 2010, 63:95-104.

18. Mohebbi S, Nikpour F, Raiati S: Homogeneous green catalyst for epoxidation of cyclooctene by mono oxovanadium(IV) complexes of N2O2 donate ligand system. J Mol Catal A: Chem 2006, 256:265-268.

19. Boghaei DM, Mohebi S: Synthesis, characterization and study of vanadyl tetradentate Schiff base complexes as catalyst in aerobic selective oxidation of olefins. J Mol Catal A: Chem 2002, 179:41-45.

20. Maurya MR, Agarwal S, Bader C, Ebel M, Rehder D: Synthesis, characterisation and catalytic potential of hydrazonatovanadium(v) model complexes with [VO]3+ and [VO 2]+ cores. Dalton Trans 2005, :537-544.

21. Reis PM, Silva JAL, Silva JJRFD, Pombeiro AJL: Peroxidative oxidation of benzene and mesitylene by vanadium catalysts. J Mol Catal A:Chem 2004, 224:189-195.

22. Reddy P, Chu C-Y, Hwang D-R, Wang S-K, Uang B-J: Recent advances in the oxovanadium mediated biaryl coupling and modified Mannich-type reaction. Coord Chem Rev 2003, 237:257-269.

23. Hon S-W, Li C-H, Kuo J-H, Barhate NB, Liu Y-H, Wang Y, Chen C-T: Catalytic asymmetric coupling of 2-naphthols by chiral tridentate oxovanadium (IV) complexes. Org Lett 2001, 3:869-872.

24. Guo Q-X, Wu Z-J, Luo Z-B, Liu Q-Z, Ye J-L, Luo S-W, Cun L-F, Gong L-Z Highly enantioselective oxidative couplings of 2-naphthols catalyzed by chiral bimetallic oxovanadium complexes with either oxygen or air as oxidant. J Am Chem Soc 2007, 129:13927-13638.

25. Luo Z, Liu Q, Gong L, Cui X, Mi A, Jiang Y: Novel achiral biphenol-derived diastereomeric oxovanadium(IV) complexes for highly enantioselective oxidative coupling of 2-naphthols. Angew Chem Int Ed 2002, 41:45324535.

26. Licini G, Conte V, Coletti A, Mba M, Zonta C: Recent advances in vanadium catalyzed oxygen transfer reactions. Coord Chem Rev 2011, 255:2345-2357.

27. da Silva JAL, da Silva JJR F, Pombeiro AJL: Oxovanadium complexes in catalytic oxidations. Coord Chem Rev 2011, 255:2232-2248.

28. Petek H, Albayrak C, Odabasoglu M, Senel I, Buyukgungor O: Crystallographic and conformational analysis of [(Z)-2-ethoxy-6-[(2hydroxyphenylamino)methylene] cyclohexa-2,4-dienone]. J Chem Crystallogr 2008, 38:901-905.

29. Nakamoto K: Infrared and Raman Spectra of Inorganic Coordination Compounds. New York, Wiley and sons:; 1978:229.

30. Syamal A, Kale KS: Magnetic and spectral properties of oxovanadium(IV) complexes of ONO donor tridentate, dibasic Schiff bases derived from salicylaldehyde or substituted salicylaldehyde and ohydroxybenzylamine. Inorg Chem 1979, 18:992-995.

31. Goodgame M, Hayward PJ: Infrared spectra (1650-400 cm.-1) of $\gamma$ picoline metal co-ordination complexes. J Chem Soc A 1966, :632-634.

32. Selbin J: The chemistry of oxovanadium(iv). Chem Rev 1965, 65:153-175.

33. Selbin J: Oxovanadium(IV) complexes. Coord Chem Rev 1966, 1:293-314.

34. Dinda R, Sengupta P, Ghosh S, Mak TCW: Valence delocalization in a mixed-oxidation divanadium (IV, V) complex electrogenerated from its structurally characterized divanadium (V) analogue with a tridentate (ONO) ligand. Inorg Chem 2002, 41:1684-1688.
35. Mathew M, Carty AJ, Palenik GJ: An unusual complex containing bridging vanadyl groups. The crystal structure of N,N/-propylenebis(salicylaldiminato)oxovanadium(IV) [12]. J Am Chem Soc 1970, 92:3197-3198.

36. Boas LV, Pessoa JC: Vanadium. In Comprehensive Coordination Chemistry Volume 5. Pergamon Press: Oxford: Edited by Willkinson G, Gillard, RD, McCleverty JA; 1987.

37. Kaitner B, Pavlovic G: Hydrogen Bonded Dimer N-(2-hydroxyethyl)-2-oxy1-naphthaldimine and Its Oxo-vanadium(V) Complex. Croat Chem Acta 1999, 72:607-620.

38. Vergopoulos V, Priebsch W, Fritzsche M, Rehder D: Binding of L-histidine to vanadium. Structure of exo-[VO2\{N-(2-oxidonaphthal)-His\}]. Inorg Chem 1993, 32:1844-1849.

39. Venkatachalam TK, Pierens GK, Campitelli MR, Reutens DC: Structural investigation on phenyl- and pyridin-2-ylamino(methylene) naphthalen2(3H)-one. Substituent effects on the NMR chemical shifts. Magn Reson Chem 2010, 48:585-592.

40. Maurya MR, Sikarwar S, Manikandan P: Oxovanadium(IV) complex of 2-(ahydroxyethyl)benzimidazole covalently bonded to chloromethylated polystyrene for oxidation of benzoin. Appl Catal A: Gen 2006, 315:74-82.

41. Skobridis K, Theodorou $V$, Weber E: A very simple and chemoselective air oxidation of benzoins to benzils using alumina. Arkivoc 2006, 10:102-106.

doi:10.1186/1752-153X-7-3

Cite this article as: Alsalim et al:: Oxidation of benzoin catalyzed by oxovanadium(IV) schiff base complexes. Chemistry Central Journal 2013 7:3.

Publish with ChemistryCentral and every
scientist can read your work free of charge
"Open access provides opportunities to our
colleagues in other parts of the globe, by allowing
anyone to view the content free of charge."
W. Jeffery Hurst, The Hershey Company.
- available free of charge to the entire scientific community
- peer reviewed and published immediately upon acceptance
- cited in PubMed and archived on PubMed Central
- yours - you keep the copyright
submit your manuscript here:
http://www.chemistrycentral.com/manuscript/

